\title{
Influence of anthropometry on race performance in extreme endurance triathletes: World Challenge Deca Iron Triathlon 2006
}

\author{
Beat Knechtle, Patrizia Knechtle, Jorge Luis Andonie, Göłz Kohler
}

Br J Sports Med 2007;41:644-648. doi: 10.1136/bjsm.2006.035014

See end of article for authors' affiliations

......................

Correspondence to: Dr Knechtle,

Gesundheitszentrum St Gallen, Switzerland;

beat.knechtle@hispeed.ch

Accepted 6 March 2007

Published Online First

7 June 2007
Objective: To investigate the influence of anthropometric variables on race performance in ultra-endurance triathletes in an ultra-triathlon.

Design: Descriptive field study.

Setting: The "World Challenge Deca Iron Triathlon 2006" in Monterrey, Mexico, in which everyday for 10 consecutive days athletes had to perform the distance of one Ironman triathlon of $3.8 \mathrm{~km}$ swimming, $180 \mathrm{~km}$ cycling and $42.195 \mathrm{~km}$ running.

Subjects: Eight male ultra-endurance athletes (mean (SD) age 40.6 (10.7) years, weight 76.4 (8.4) kg, height $175(4) \mathrm{cm}$ and body mass index (BMI) $\left.24.7(2.2) \mathrm{kg} / \mathrm{m}^{2}\right)$.

Interventions: None.

Main outcome measures: Direct measurement of body mass, height, leg length, skinfold thicknesses, limb circumference and calculation of BMI, skeletal muscle mass (SM), percentage SM (\%SM) and percentage body fat $(\% \mathrm{BF})$ in order to correlate measured and calculated anthropometric variables with race performance.

Results: Race time was not significantly $(p>0.05)$ influenced by the directly measured variables, height, leg length, body mass, average skinfold thicknesses, or circumference of thigh, calf or upper arm. Furthermore, no significant $(p>0.05)$ correlation was observed between race time and the calculated variables, BMI, \%SM and \%BF.

Conclusions: In a multistage ultra-triathlon over 10 Ironman triathlon distances in 10 consecutive days, there was no effect of body mass, height, leg length, skinfold thicknesses, limb circumference, BMI, \%SM or \%BF on race performance in the only eight finishers. $\mathrm{n}$ endurance racing, there are many factors that influence performance. Apart from several physiological variables, a variety of anthropometric variables have been shown to have an effect on endurance performance: body mass, ${ }^{12}$ body mass index (BMI), ${ }^{3}$ body fat, ${ }^{3}$ length of the upper leg, ${ }^{4}$ length of limbs, ${ }^{5}$ height, ${ }^{16}$ thigh girth, ${ }^{4}$ total skinfolds ${ }^{1}$ and skinfold thickness of the lower limb. ${ }^{78}$

In a review, Berg 9 attempted to enhance our knowledge of the effects of anthropometry on running performance. Anthropometric properties and their effect on exercise performance have previously been investigated during short and middle distance running and marathons, ${ }^{78}$ but data for ultradistance running are lacking. In this investigation, anthropometric data of the only eight male finishers of the "World Challenge Deca Iron Triathlon 2006" in Mexico were analysed with respect to their influence on race time. We expected that a low BMI would have an effect on race performance. We also assumed that a high percentage of body fat would impair race performance.

\section{SUBJECTS AND METHODS \\ Subjects}

The organiser of the "World Challenge Deca Iron Triathlon 2006" contacted all participants by separate newsletter 3 months before the race to ask them to participate in our investigation. Fourteen male and three female caucasian ultratriathletes started the race; eight male athletes (mean (SD) age 40.6 (10.7) years, weight $76.4(8.4) \mathrm{kg}$, height $1.75(0.04) \mathrm{m}$, BMI $24.7(2.2) \mathrm{kg} / \mathrm{m}^{2}$ ) and one female athlete ( 33 years, $56 \mathrm{~kg}$, $1.70 \mathrm{~m}, 19.4 \mathrm{~kg} / \mathrm{m}^{2}$ ) finished the race within the time limit. Of the six unsuccessful male athletes, one had to give up because of technical problems with his bike, one was disqualified because of drafting during cycling, one had problems with his buttocks during cycling and was unable to continue the race, two were out beyond the limit after day 2 , and one was beyond the time limit after day 3. Only the eight male athletes who successfully finished were included in the study. They all gave their informed written consent. Mean (SD) training for the race was 24 (11) h a week (range 10-45). They had a mean experience of 18 (range 1-52) extreme endurance races of $24 \mathrm{~h}$ and longer before the start of this race.

\section{The race}

The World Challenge Deca Iron Triathlon 2006 was held in November 2006 as a world premiere in ultra-triathlon. The race took place in the city of Monterrey in the Province of Nuevo León in northern Mexico, about $230 \mathrm{~km}$ south of the border with the USA. Monterrey is the capital of Nuevo León; it is $540 \mathrm{~m}$ above sea level and has more than one million inhabitants. In November, the temperature in Monterrey varies between 16 and $28^{\circ} \mathrm{C}$, but it can drop from one day to another down to $10^{\circ} \mathrm{C}$ and increase to $36^{\circ} \mathrm{C}$ and higher. Usually there is no rain and only a little wind. The race started on 6 November 2006. Seventeen experienced and well-prepared ultra-endurance athletes (14 male, three female) from 10 different countries and three continents qualified to enter the race. Everyday they had to perform the distance of one Ironman

Abbreviations: \%BF, percentage body fat; $\mathrm{BMI}$, body mass index; $\mathrm{SM}$, skeletal muscle mass 
triathlon of $3.8 \mathrm{~km}$ swimming, $180 \mathrm{~km}$ cycling and $42.195 \mathrm{~km}$ running. Every morning at 09:00, the event started with the swim in the $50 \mathrm{~m}$ outdoor pool in the park of Sociedad Cuauhtemoc \& Famosa in Monterrey, $3 \mathrm{~km}$ away from the cycling and running track in the Parque Niños Héroes. The water temperature in the Olympic pool was $17-21^{\circ} \mathrm{C}$. Laps of $100 \mathrm{~m}$ were counted by personal lap counters for each athlete.

After completing the swim, athletes were transferred by car to the Parque Niños Héroes. A period of 30 min was allowed for the transfer from the pool to the competition site and the time was deducted from the final race time. The park was closed to traffic, completely illuminated, and had a cycling track that was $95 \%$ flat, but included an inclination of $5 \%$. The cycling consisted of 94 laps of $1.915 \mathrm{~km}$ each. After changing for the running course, athletes first had to run a short lap of $703 \mathrm{~m}$ and then 22 laps of $1.886 \mathrm{~km}$. Athletes could be helped by their own support crew. Drafting during cycling was prohibited. Laps in the park were counted electronically with a chip system. Table 1 presents the weather conditions and the highest temperature during the day.

During the whole race, accommodation was offered in the sports village of the park, about $250 \mathrm{~m}$ away from the race site. Athletes had a room with bed, toilet and shower. For nutrition, the organiser offered a variety of food in a restaurant which was open $24 \mathrm{~h}$ : spaghetti, rice, baked potatoes, meat with tomato sauce, bread, eggs, eggs with ham, eggs with beans, eggs with sausage, hot cakes, pastries, sandwiches, tacos, sausages, soups, hot dogs, hamburgers, chicken, fish, oatmeal, cereals, French toast, salad, vegetables, granola bars, cookies, marmalade, cereals, salt, sugar, butter, honey, bananas, oranges, apples, orange juice, Powerade, Coca Cola, purified water, mineral water, tea, milk, chocolate milk, strawberry milk, banana milk, vanilla cake with strawberry and pineapple, and chocolate cake with coconut cream.

\section{Measurements and calculations}

The evening before the start of the race, body mass, leg length, circumference of upper arm, thigh and calf, and skinfold thickness at eight regions were measured. Body mass was measured with commercial scales (Beurer BF 15; Beurer GmbH, Ulm, Germany) to the nearest $0.1 \mathrm{~kg}$. Skinfold thicknesses, leg length and limb circumferences were measured on the right side of the body. Every measurement was taken three times by the same person, and the mean value was used for calculation. Length of the upper leg was measured from the trochanter major to the meniscus lateralis, and the length of the lower leg from the meniscus lateralis to the malleolus lateralis. The largest circumference of the upper arm and calf were measured to the nearest $0.1 \mathrm{~cm}$. The circumference of the thigh was

Table 1 Highest temperature during the day, the temperature of the water in the pool, and the general weather conditions during the race

\begin{tabular}{llll}
\hline & $\begin{array}{l}\text { Air } \\
\text { temperature } \\
\text { ('C) }\end{array}$ & $\begin{array}{l}\text { Water } \\
\text { temperature } \\
\text { ('C) }\end{array}$ & Weather \\
\hline 1 & 28.5 & 19 & Sun, little wind \\
2 & 28.8 & 19 & Sun, little wind \\
3 & 30.1 & 19 & Sun, little wind \\
4 & 34.9 & 20 & Sun, little wind \\
5 & 35.9 & 21 & Sun, little wind \\
6 & 20.3 & 17 & Clouds, moderate wind \\
7 & 22.1 & 17 & Clouds, little wind \\
8 & 25.7 & 18 & Sun, heavy wind \\
9 & 30.9 & 19 & Sun, moderate wind \\
10 & 23.9 & 19 & Sun, heavy wind \\
\hline
\end{tabular}

determined $15 \mathrm{~cm}$ above the upper pole of the patella. Skinfold thickness at the chest, midaxillary (vertical), triceps, subscapular, abdominal (vertical), suprailiac (at the anterior axillary), thigh and calf was measured with a skinfold calliper (GPMHautfaltenmessgerät; Siber \& Hegner, Zurich, Switzerland) to the nearest $0.2 \mathrm{~mm}$. Skeletal muscle mass (SM) was calculated using the following formula:

$$
\begin{aligned}
\mathrm{SM}= & \mathrm{Ht} \times\left(0.00744 \times \mathrm{CAG}^{2}+0.00088 \times \mathrm{CTG}^{2}+0.00441 \times\right. \\
& \left.\mathrm{CCG}^{2}\right)+2.4 \times \mathrm{sex}-0.048 \times \text { age }+ \text { race }+7.8
\end{aligned}
$$

where $\mathrm{Ht}=$ height, $\mathrm{CAG}=$ skinfold-corrected upper arm girth, CTG = skin fold-corrected thigh girth, CCG = skinfoldcorrected calf girth, sex $=1$ for male, race $=0$ for white. ${ }^{10}$ Percentage SM (\%SM) was achieved by dividing SM by body mass and multiplying by $100 \%$. Percentage body fat (\%BF) was calculated using the following formula:

$$
\begin{aligned}
\% \mathrm{BF}= & 0.465+0.180(\Sigma 7 \mathrm{SF})-0.0002406(\Sigma 7 \mathrm{SF})^{2}+ \\
& 0.0661(\text { age })
\end{aligned}
$$

where $\Sigma 7 \mathrm{SF}=$ sum of skinfold thickness of chest, midaxillary, triceps, subscapular, abdomen, suprailiac and thigh mean. ${ }^{11}$

\section{Statistical analysis}

Anthropometric variables were correlated with race time. Statistical analysis was performed with the R software package (R Foundation for Statistical Computing, Vienna, Austria, 2005). Forward selection of the predictor variables was used in the multiple regression analysis to identify the performancerelevant anthropometric variables. As anthropometric properties can be described by several dependent variables, the directly measured predictors (body mass, height, mean skin fold thickness, leg length and circumference of the calf, thigh and upper arm) and the calculated predictors (BMI, \%BF and $\% \mathrm{SM}$ ) were separated into two independent models. For all statistical tests, the significance level was set to 0.05 .

\section{RESULTS}

Table 2 shows the anthropometric data of the finishers before the race. The race time was not significantly $(\mathrm{p}>0.05)$ influenced by the directly measured anthropometric properties, height, body mass, mean skinfold thickness or circumference of thigh, calf and upper arm (fig 1) or leg length (fig 2). Furthermore, no significant $(\mathrm{p}>0.05)$ correlation was observed

Table 2 Anthropometric properties of the eight male finishers before the start of the race

\begin{tabular}{ll}
\hline Variable & Mean (SD) \\
\hline Body mass (kg) & $76.4(8.4)$ \\
Height (m) & $1.75(0.04)$ \\
Length of upper leg (cm) & $45.0(1.8)$ \\
Length of lower leg (cm) & $40.3(2.9)$ \\
Length of whole leg (cm) & $85.4(3.4)$ \\
Circumference of upper arm (cm) & $30.6(2.4)$ \\
Circumference of thigh (cm) & $56.4(5.1)$ \\
Circumference of calf (cm) & $38.7(2.5)$ \\
Skinfolds (mm) & $4.8(1.2)$ \\
Pectoral & $5.6(1.2)$ \\
Axillary & $6.2(1.8)$ \\
Triceps & $8.3(1.8)$ \\
Subscapular & $11.6(3.1)$ \\
Abdominal & $10.3(5.3)$ \\
Suprailiac & $8.5(3.4)$ \\
Thigh & $7.0(2.9)$ \\
Calf & $24.7(2.2)$ \\
Body mass index (kg/m $\left.{ }^{2}\right)$ & $40.2(5.3)$ \\
Skeletal muscle mass (kg) & $12.3(1.6)$ \\
\% Body fat & \\
\hline The variables are grouped as directly measured (body mass, \\
height, leg length, limb circumference, mean skinfold thickness) \\
and calculated (body mass index, skeletal muscle mass, \% body \\
fat) as used for the multiple regression analysis.
\end{tabular}




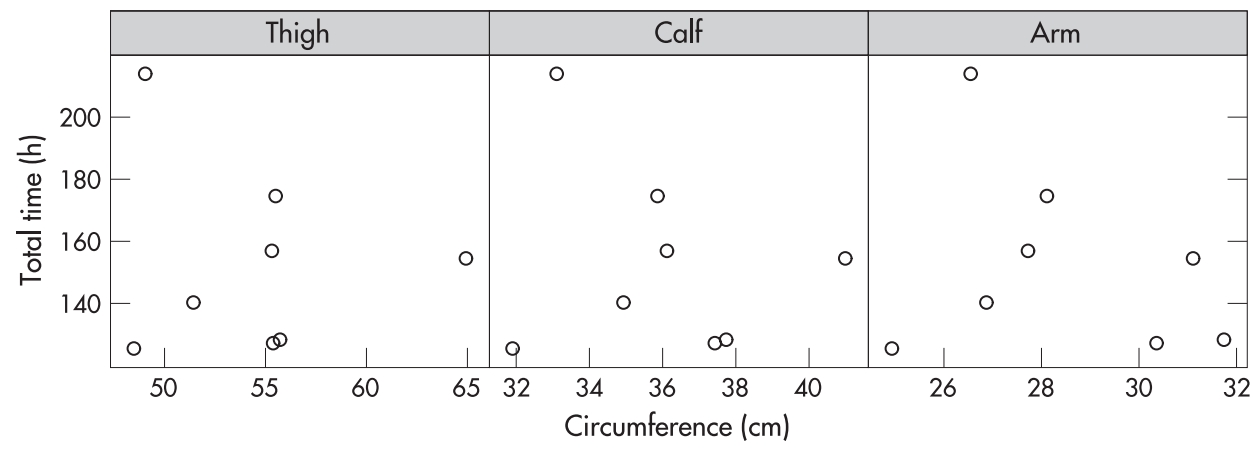

Figure 1 Effect of limb circumferences (upper arm, upper leg and lower leg) on race time in the World Challenge Deca Iron Triathlon 2006. between race time and the calculated variables, BMI, \%BF and \%SM (fig 3).

\section{DISCUSSION}

The main finding of this investigation is that none of the anthropometric factors previously found to affect performance, such as body fat, ${ }^{3}$ thigh girth, ${ }^{4}$ total skinfolds, ${ }_{1}{ }^{1}$ BMI, ${ }^{3}$ body mass, ${ }^{12}{ }^{2}$ length of the upper leg, ${ }^{4}$ length of limbs, ${ }^{5}$ and skinfold thickness of the lower limb, ${ }^{78}$ were confirmed in this group of finishers in the World Challenge Deca Iron Triathlon 2006. In contrast with the effect in these ultra-triathletes, several anthropometric factors have been found to influence performance in runners. The effect of weight, body mass, skinfold thicknesses and body fat has been described in runners in several studies. We assume that there must be differences between triathletes and runners, or our study group was too small to find statistically significant differences.

\section{Effect of body mass and BMI on running performance}

The effects of body mass and BMI on performance have been investigated in several studies, usually with runners. A positive effect of BMI on performance has been found in African endurance athletes in particular. African runners are smaller ${ }^{12} 13$ and lighter than caucasian runners, ${ }^{12}{ }^{14}$ which could not be confirmed in the study of Rahmani et al. ${ }^{15}$ However, Rahmani et al investigated the effect of body mass on race performance in sprinters. African long distance runners have a lower BMI than caucasian runners. A BMI of $19.2 \mathrm{~kg} / \mathrm{m}^{2}$ was found for Kenyan runners compared with $20.6 \mathrm{~kg} / \mathrm{m}^{2}$ for the best Scandinavian runners. ${ }^{16}$ When Senegalese and Italian runners were compared, the African runners had longer and lighter legs. ${ }^{15}$ It is thought that their lower $\mathrm{BMI}^{17}$ and smaller body size are important in the better performance of the African runners. ${ }^{18}$ In addition to African runners, a relation between BMI and race performance has also been found in female caucasian marathon runners: marathon race time correlated positively with BMI. ${ }^{3}$ Obviously, the absolute value of BMI seems to be of importance. The BMI of our ultra-triathletes is higher than that found for Kenyan runners:
$24.7 \mathrm{~kg} / \mathrm{m}^{2}$ (table 2) compared with $18.6 \mathrm{~kg} / \mathrm{m}^{2}$ for young Kenyan runners $^{19}$ and $19.2 \mathrm{~kg} / \mathrm{m}^{2}$ for adult Kenyan runners. ${ }^{16}$ It is of interest that the BMI of the unsuccessful competitors in the race investigated here was $23.5 \mathrm{~kg} / \mathrm{m}^{2}$ and therefore lower than that of the finishers. A lower BMI was obviously not advantageous in this race.

\section{Influence of body fat on performance in runners}

It is known from several studies that body fat affects the performance of runners. An excess of subcutaneous adipose tissue means that greater muscular effort and therefore increased energy expenditure is required. It has been shown that physical performance is negatively related to body fat and positively related to skeletal muscle mass. ${ }^{20}{ }^{21}$ This was confirmed in a recent study. ${ }^{7}$ The loss of body fat is specific to selected muscle groups used during training, and race performance is enhanced with decreased skinfold thickness at the lower limb. ${ }^{8}$ Body fat seems to have a special effect in runners, especially African runners. They have a lower skinfold thickness at the legs and $\operatorname{arms}^{14}$ suggesting a smaller mass of subcutaneous adipose tissue. In other studies, the effect of body fat on race performance is controversial. Whereas Hagan et al ${ }^{3}$ found a positive correlation between marathon performance time and body fat in female runners, Christensen and Ruhling ${ }^{22}$ found that \%BF did not correlate with finish times.

\section{Skinfold thicknesses and their effect on running performance}

The effect of skinfold thickness on running performance has been investigated in both older and more recent studies. ${ }^{1} 782324$ Decreased leg skinfold thicknesses have been reported in runners; this may be particularly useful in predicting running performance. ${ }^{8}$ Legaz and Eston ${ }^{8}$ found an association between decreased thigh skinfold thickness and improved performance. Furthermore, Bale et $\mathrm{al}^{1}$ found that total skinfolds, among other variables such as type and frequency of training and the number of years of running, were the best predictors of running performance and success over $10000 \mathrm{~m}$. Arrese and Ostariz

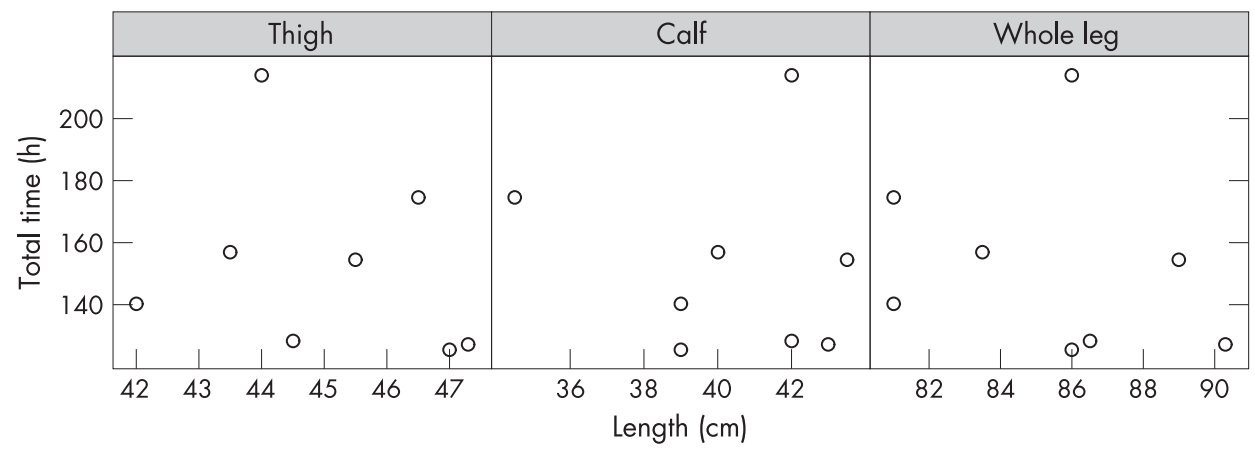

Figure 2 Effect of leg length (lower leg, upper leg and whole leg) on race time in the World Challenge Deca Iron Triathlon 2006. 


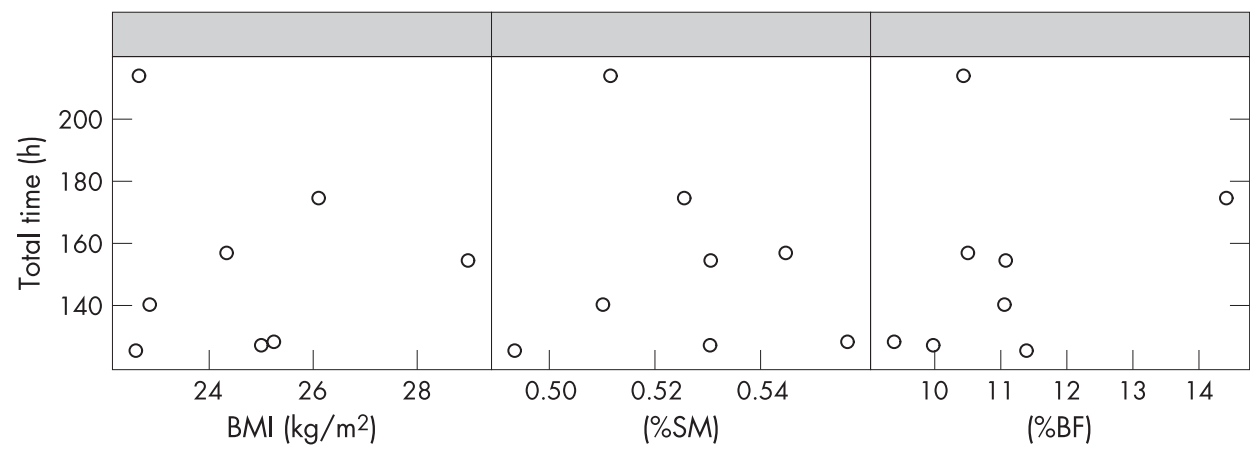

Figure 3 Effect of the calculated variables body mass index (BMI), percentage skeletal muscle mass $(\% \mathrm{SM})$ and percentage body fat (\%BF) on race times in the World Challenge Deca Iron Triathlon 2006. showed a high correlation between the thigh and calf skinfolds and $1500 \mathrm{~m}$ as well as $10000 \mathrm{~m}$ race times. In earlier studies, this effect was not reported. ${ }^{23-25}$ No differences were found in skinfold values among runners competing in classical distances ranging from $100 \mathrm{~m}$ to $10000 \mathrm{~m}^{25}$ Conley and Krähenbühl ${ }^{23}$ reported no significant relation between body fat or sum of skinfolds in an elite group of $10000 \mathrm{~m}$ runners, and Kenney and Hodgson ${ }^{24}$ showed similar findings in $3000 \mathrm{~m}$ steeplechase runners. There are two major differences in the studies of Bale et al, ${ }^{1}$ Arrese and Ostariz ${ }^{7}$ and Legaz and Eston ${ }^{8}$ from our study. Firstly, in their studies, running performances in events of $10000 \mathrm{~m}$ and less were investigated. Our ultra-triathletes had to run a total distance of $126.6 \mathrm{~km}$ after cycling and swimming.

Secondly, the measured leg skinfold thicknesses are thought to be different in runners and ultra-triathletes. Ultra-triathletes seem to have thicker skinfolds than shorter-distance runners. Our ultra-triathletes had a skinfold thickness of 8.5 (3.4) mm at the thigh and $7.0(2.9) \mathrm{mm}$ at the calf (table 2) compared with $9.4(4.2) \mathrm{mm}$ at the thigh and $4.6(1.3) \mathrm{mm}$ at the calf in the runners in the study of Legaz and Eston. ${ }^{8}$ The length of the race seems to be important in the correlation between skinfold thickness and race performance. Arrese and Ostariz ${ }^{7}$ found that marathon runners had a lower sum of six skinfolds than runners of distances up to $10000 \mathrm{~m}$. They concluded that $(a)$ the training volume of marathon runners is higher and $(b)$ in marathon running, fat metabolism dominates in training and competition. Interestingly, our ultra-athletes had a higher sum of six skinfolds than the marathon runners of Arrese and Ostariz (51.7 vs $44.4 \mathrm{~mm}$ ). The value of $51.7 \mathrm{~mm}$ for our triathletes is near the value of $51.4 \mathrm{~mm}$ found for $1500 \mathrm{~m}$ runners by Arrese and Ostariz. ${ }^{7}$

\section{What is already known on this topic}

In runners, a variety of anthropometric variables, such as body mass, body mass index, body fat, length of the upper leg, total leg length, height, thigh girth, total skinfolds and skinfold thickness of the leg, have been shown to affect endurance performance.

\section{What this study adds}

In the only eight male finishers of the World Challenge Deca Iron 2006 (10 times one Ironman triathlon within 10 consecutive days), body mass, height, mean skinfold thickness, leg length and circumference of the calf, thigh and upper arm, as well as the calculated values body mass index, percentage fat mass and percentage skeletal muscle mass, showed no effect on race performance.

\section{Anthropometric factors in triathletes}

In triathletes compared with runners, different morphological factors seem to be important. Landers et $a l^{5}$ found that robustness, adiposity, segmental length of limbs, and skeletal muscle mass are important. Also, it is known that body fat has affects race performance in triathletes. ${ }^{26}$ Successful elite triathletes have been described as generally tall, of averageto-light weight, with low levels of body fat. ${ }^{26}$ In an Ironman triathlon, starting body weight is significantly related to total finishing time and also to cycling and running time. ${ }^{2}$

\section{Other aspects of anthropometric factors in runners and triathletes}

Other factors have also been discussed for runners. In middle and long distance runners, length of the upper leg and thigh girth are related to performance, ${ }^{4}$ and in marathon runners different physiological variables can explain the variance in marathon times among elite runners. ${ }^{25}$ In triathletes, there is no ideal or unique anthropometric profile with respect to performance, ${ }^{27}$ and training parameters seem to be more important than anthropometric measures in the prediction of performance. $^{12228}$ In marathon finishers, the most mileage covered per training session is the best predictor of successful completion of a marathon. ${ }^{29}$ Total training time at low intensities seems to be associated with improved performance in highly intense events, ${ }^{30}$ but an upper limit in training volume exists, above which there are no further improvements in race performance. ${ }^{31}$

\section{Limitations of the study}

In this world premiere, only 14 male athletes started and only the eight official finishers could be included in our investigation. This limits the statement that no effect of anthropometric data on race performance was found. In contrast, Arrese and Ostariz $^{7}$ studied 184 top-class runners, and Legaz and Eston ${ }^{8}$ investigated a total of 35 athletes.

\section{CONCLUSION}

To summarise, in a multistage ultra-triathlon over 10 times an Ironman triathlon within 10 consecutive days, we found no correlation between race performance and body mass, height, skinfold thicknesses, leg length, limb circumference, \%SM or $\% \mathrm{BF}$ in the eight male finishers. It can be assumed that ultratriathletes have a different body composition from runners, and therefore cannot be compared with runners, who are more affected by anthropometric factors. Triathletes seem to have greater anthropometric variability than runners, because triathletes have to train for and perform three different disciplines. Studies on the effect of anthropometry on race performance have mainly been on runners of distances from $100 \mathrm{~m}$ to $10000 \mathrm{~m}$ and marathons. We would welcome more studies on the influence of anthropometry on endurance performance, with a greater number of triathletes over short 
and long distances; there seems to be enough literature on anthropometric effects on performance in runners, but very little is known on this subject in triathletes.

\section{Authors' affiliations}

Beat Knechtle, Patrizia Knechtle, Gesundheitszentrum St Gallen, Switzerland

Jorge Luis Andonie, Multisport Andonie, Monterrey, Nuevo Leon, Mexico Götz Kohler, Division of Biophysical Chemistry, Biozentrum, University of Basel, Basel, Switzerland

Competing interests: None.

\section{REFERENCES}

1 Bale $\mathbf{P}$, Bradbury D, Colley E. Anthropometric and training variables related to $10 \mathrm{~km}$ running performance. Br J Sports Med 1986;20:170-3.

2 Sharwood K, Collins M, Goedecke J, et al. Weight changes, sodium levels, and performance in the South African Ironman triathlon. Clin J Sport Med 2002;12:391-9.

3 Hagan RD, Upton SJ, Duncan JJ, et al. Marathon performance in relation to maximal aerobic power and training indices in female distance runners. Br J Sports Med 1987;21:3-7

4 Tanaka K, Matsuura Y. A multivariate analysis of the role of certain anthropometric and physiological attributes in distance running. Ann Hum Biol 1982;9:473-82.

5 Landers GJ, Blanksby BA, Ackland TR, et al. Morphology and performance of world championship triathletes. Ann Hum Biol 2000;27:387-400.

6 Maldonado S, Mujika I, Padilla S. Influence of body mass and height on the energy cost of running in highly trained middle- and long-distance runners. Int J Sports Med 2002;23:268-72.

7 Arrese AL, Ostariz ES. Skinfold thicknesses associated with distance running performance in highly trained runners. J Sports Sci 2006;24:69-76.

8 Legaz A, Eston R. Changes in performance, skinfold thicknesses, and fat patterning after three years of intense athletic conditioning in high level runners. Br J Sports Med 2005;39:851-6.

9 Berg K. Endurance training and performance in runners: research limitations and unanswered questions. Sports Med 2003;33:59-73.

10 Lee RC, Wang Z, Heo M, et al. Total-body skeletal muscle mass: development and cross-validation of anthropometric prediction models. Am J Clin Nutr 2000;72:796-803.

11 Ball SD, Altena TS, Swan PD. Comparison of anthropometry to DXA: a new prediction equation for men. Eur J Clin Nutr 2004;58:1525-31.

12 Weston AR, Karamizrak O, Smith A, et al. African runners exhibit greater fatigue resistance, lower lactate accumulation, and higher oxidative enzyme activity. J Appl Physiol 1999;86:915-23.

13 Weston AR, Mbambo Z, Myburgh KH. Running economy in African and Caucasian distance runners. Med Sci Sports Exerc 2000;32:1130-4.

14 Bosch AN, Goslin BR, Noakes TD, et al. Physiological differences between black and white runners during a treadmill marathon. Eur J Appl Physiol 1990;61:68-72.

15 Rahmani A, Locatelli E, Lacour JR. Differences in morphology and force/velocity relationship between Senegalese and Italian sprinters. Eur J Appl Physiol 2004;91:399-405.

16 Saltin B, Larsen H, Terrados N, et al. Aerobic exercise capacity at sea level and at altitude in Kenyan boys, junior and senior runners compared with Scandinavian runners. Scand J Med Sci Sports 1995;5:209-21.

17 Larsen HB. Kenyan dominance in distance running. Comp Biochem Physiol A Mol Integr Physiol 2003;136:161-70.

18 Marino FE, Lambert MI, Noakes TD. Superior performance of African runners in warm humid but not in cool environmental conditions. J Appl Physiol 2004;96:124-30.

19 Larsen HB, Christensen DL, Nolan T, et al. Body dimensions, exercise capacity and physical capacity level of adolescent Nandi boys in western Kenya. Ann Hum Biol 2004;31:159-73.
20 Leedy HE, Ismail AH, Kessler WV, et al. Relationships between physical performance items and body composition. Res Q 1965;36:158-63.

21 Riedenau RP, Welch BE, Crips CE, et al. Relationship of body fat to motor fitness test scores. Res Q 1968;29:200-3.

22 Christensen CL, Ruhling RO. Physical characteristics of novice and experienced women marathon runners. Br J Sports Med 1983;17:166-71.

23 Conley DL, Krähenbühl GS. Running economy and distance running performance of highly trained athletes. Med Sci Sports Exerc 1980;12:357-60.

24 Kenney L, Hodgson L. Variables predictive of performance in elite middledistance runners. Br J Sports Med 1985;19:207-9.

25 Legaz Arrese A, Gonzalez Badillo JJ, Serrano Ostariz E. Differences in skinfold thicknesses and fat distribution among top-class runners. J Sports Med Phys Fitness 2005;45:512-17.

26 Sleivert GG, Rowlands DS. Physical and physiological factors associated with success in the triathlon. Sports Med 1996;22:8-18.

27 Laurenson NM, Fulcher KY, Korkia P. Physiological characteristics of elite and club level female triathletes during running. Int J Sports Med 1993;14:455-9.

28 Bale P, Rowell S, Colley E. Anthropometric and training characteristics of female marathon runners as determinants of distance running performance. J Sports Sci 1985;3:115-26.

29 Yeung SS, Yeung EW, Wong TW. Marathon finishers and non-finishers characteristics. A preamble to success. J Sports Med Phys Fitness 2001;41:170-6.

30 Esteve-Lanao J, San Juan AF, Earnest CP, et al. How do endurance runners actually train? Relationship with competition performance. Med Sci Sports Exerc 2005;37:496-504.

31 Sjödin B, Svedenhag J. Applied physiology of marathon running. Sports Med 1985;2:83-99.

\section{COMMENTARY}

In correlations of anthropometric data with performance, whether the investigated group is homogeneous or heterogeneous should be determined. A significantly positive relationship between body mass and running time can exist for a group of sprinters who are heterogeneous with respect to body composition, as a high fat percentage can induce high body mass, resulting in inferior running performance. On the other hand, a high body mass may also reflect a large muscle mass compartment in a well-trained homogeneous group of sprinters, which might lead to a better running time and thus a negative correlation between running time and body mass. In kinanthropometry and sports anthropology, the different running disciplines have so far been well examined for these relationships. However, there is a scientific gap with respect to connections between anthropometry, body composition and triathlon performance. The authors report here that race time is not significantly influenced by directly measured anthropometric and calculated variables. It might be of further interest, however, to determine which relationships would have been found in a less homogeneous group with respect to performance level, body composition and somatotype.

Christoph Josef Raschka Universität Frankfurt, Institut Für Sportwissenschaften, Germany; craschka@gmx.de 